\title{
Similar microearthquakes observed in western Nagano, Japan, and implications for rupture mechanics
}

\author{
Xin Cheng, ${ }^{1}$ Fenglin Niu, ${ }^{1}$ Paul G. Silver, ${ }^{2}$ Shigeki Horiuchi, ${ }^{3}$ Kaori Takai, ${ }^{3}$ \\ Yoshihisa Iio, ${ }^{4}$ and Hisao Ito ${ }^{5}$ \\ Received 28 March 2006; revised 8 November 2006; accepted 27 November 2006; published 14 April 2007.
}

[1] We have applied a waveform cross correlation technique to study the similarity and the repeatability of more than 21,000 microearthquakes $(0<M<4.5)$ in the aftershock zone of the 1984 western Nagano earthquake in central Japan. We find that the seismicity in this particular intraplate fault essentially consists of no repeating earthquakes that occurred on the same patch of the fault in a quasiperiodic manner in the study period between 1995 and 2001. On the other hand, we identify a total of 278 doublets and 62 multiplets (807 events) that occurred consecutively within seconds to days. On the basis of the relative arrival times of the $P$ and $S$ waves, we have obtained precise relative locations of these consecutive events with an error between several meters to a few tens of meters. There is a clear lower bound on the distances measured between these consecutive events and the lower bound appears to be proportional to the size of the first events. This feature is consistent with what Rubin and Gillard [2000] have observed near the San Juan Bautista section of the San Andreas Fault. Shear stress increases at the edge of an earthquake rupture, and the rupture edge becomes the most likely place where the second events are initiated. The observed minimum distance thus reflects the rupture size of the first events. The minimum distance corresponds to the rupture size calculated from a circular fault model with a stress drop of $10 \mathrm{MPa}$. We found that using different time windows results in a slight difference in the delay time estimates and the subsequent projection locations, which may reflect the finite size nature of earthquake ruptures.

Citation: Cheng, X., F. Niu, P. G. Silver, S. Horiuchi, K. Takai, Y. Iio, and H. Ito (2007), Similar microearthquakes observed in western Nagano, Japan, and implications for rupture mechanics, J. Geophys. Res., 112, B04306, doi:10.1029/2006JB004416.

\section{Introduction}

[2] Repeating earthquakes are a series of earthquakes regularly occurring on a patch of a fault plane. These earthquakes usually have approximately the same magnitude with roughly the same repeating interval. They are commonly interpreted as repeated ruptures of a single asperity surrounded by a stably sliding area [e.g., Nadeau et al., 1995]. Repeating earthquakes have been found in several sections of the San Andreas Fault [Ellsworth, 1994; Nadeau et al., 1995] and in subduction zones, such as in northeast Japan [Igarashi et al., 2003]. These regions are characterized by either a large surface creep rate or a low seismic coupling coefficient. Also, for the sections where

\footnotetext{
${ }^{1}$ Department of Earth Science, Rice University, Houston, Texas, USA.

${ }^{2}$ Department of Terrestrial Magnetism, Carnegie Institution of Washington, Washington, D. C., USA.

${ }^{3}$ National Research Institute for Earth Science and Disaster Prevention, Tsukuba, Japan.

${ }^{4}$ Disaster Prevention Research Institute, Kyoto University, Kyoto, Japan.

${ }^{5}$ Geological Survey of Japan, Tsukuba, Japan.
}

Copyright 2007 by the American Geophysical Union. 0148-0227/07/2006JB004416\$09.00 repeating earthquake sequences are found in the San Andreas Fault, fault zone trapped wave studies [ $\mathrm{Li}$ et al., 1998, 2003] indicate the presence of a well-developed low-velocity zone along the fault.

[3] Because of the close location and similar source mechanism, repeating earthquakes usually produce nearly identical seismograms when recorded at the same station. Besides the repeating events, some adjacent immediate aftershocks are also observed to have very similar waveforms [Rubin and Gillard, 2000]. Here we discriminate the two types of similar events in terms of their spatial distribution. We define repeating events as earthquakes with approximately the same magnitude and their relative centroids distance being much smaller than the rupture radii, whereas the centroids of adjacent immediate aftershocks (following Rubin and Gillard [2000], hereafter referred as to consecutive events) are located outside of their rupture areas. Because of the high waveform similarity between repeating and consecutive earthquakes, they have been widely used to study rupture size and interaction of immediate adjacent aftershocks [Rubin and Gillard, 2000], as well as to detect temporal variations in seismic velocity near fault zones, either coseismic or aseismic [Dodge and Beroza, 1997; Schaff and Beroza, 2004; Niu et al., 2003]. 


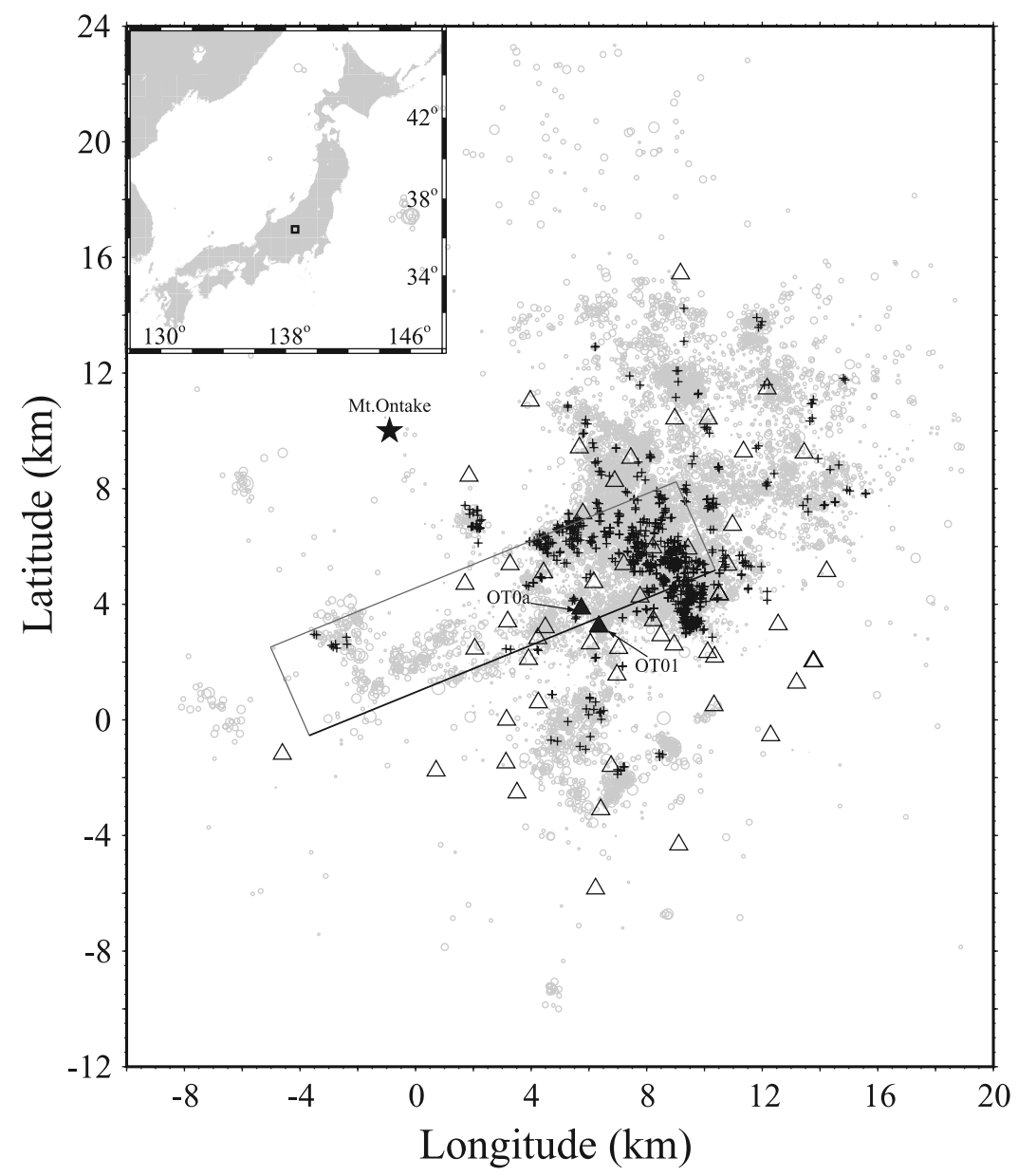

Figure 1. Geographic location of the aftershock area of 14 September 1984 Nagano earthquake in central Japan. Earthquakes and stations are shown as dots and triangles, respectively. The rectangle (is the fault plane of the main shock determined by Yoshida and Koketsu [1990]. The fault dips roughly to the north at an angle of $70^{\circ}$ with the upper boundary (thick solid line) being $0.3 \mathrm{~km}$ below the surface. Crosses indicate the locations of the identified 807 similar events. The epicenter of the 1984 earthquake $\left(35.79^{\circ} \mathrm{N}, 137.49^{\circ} \mathrm{E}\right)$ is taken as the origin of the coordinate. The fault plane is defined by four points: $\left(35.7851^{\circ} \mathrm{N}, 137.4493^{\circ} \mathrm{E}, 0.3 \mathrm{~km}\right),\left(35.8365^{\circ} \mathrm{N}, 137.6050^{\circ} \mathrm{E}, 0.3 \mathrm{~km}\right),\left(35.8641^{\circ} \mathrm{N}, 137.5900^{\circ} \mathrm{E}, 9.9 \mathrm{~km}\right)$, $\left(35.8127^{\circ} \mathrm{N}, 137.4343^{\circ} \mathrm{E}, 9.9 \mathrm{~km}\right)$. Two solid triangles indicate the two borehole stations OT0a and OT01.

[4] In this study we analyzed the waveform data of more than 21,000 microearthquakes with a magnitude between 0 and 4.5 occurring between 1995 and 2001 in the aftershock zone of the 1984 western Nagano earthquake in central Japan (Figure 1) to investigate the similarity and repeatability of these events. We chose the study area largely based on the availability of high quality array data and high seismicity in this region. With the data we first search for similar events. We further investigate the existence of repeating and consecutive events in this particular intraplate environment and examine whether rupture can reoccur immediately.

\section{Data and Waveform Similarity Measurements}

[5] A magnitude 6.8 shallow earthquake (roughly rightlateral strike slip) occurred in western Nagano in central Japan on 14 September 1984. The earthquake was followed by aftershocks that subsided after several years. However, several $M=5+$ earthquakes occurred during 1993-1995 in the same region, and since then, a high level of seismicity has been observed. A very dense seismic network with 56 stations including two borehole seismometers was set up to monitor the high level seismic activity in 1995. Each station is equipped with a three-component velocity transducer and a 16-bit analog-to-digital converter. The sensor has a natural frequency of $2 \mathrm{~Hz}$ and the system has a flat frequency response up to $4 \mathrm{kHz}$ [Iio et al., 1999]. Triggered data have been recorded at a very high sampling rate of $10 \mathrm{kHz}$. A total of 21,000 microearthquakes with magnitudes between 0 and 4.5 were recorded between 1995 and 2001. Locations of those events were routinely determined from the $P$ and $S$ wave arrival times automatically picked using the method proposed by Horiuchi et al. [1992]. We manually checked the arrival times and then used them to relocate the earthquakes with 

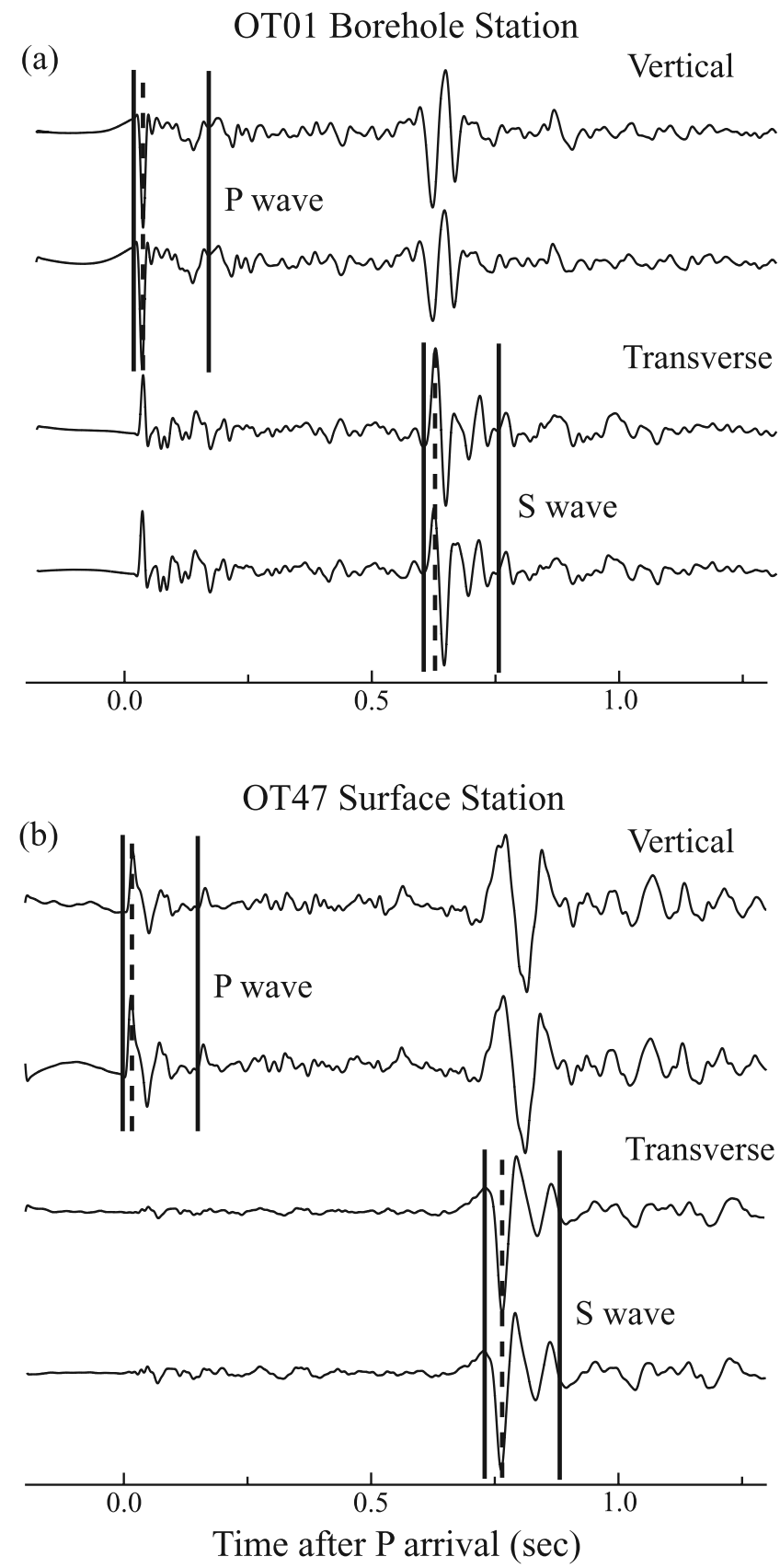

Figure 2. Examples of seismograms of two similar events recorded at (a) the 150-m-deep borehole station OT01 and (b) a surface station OT47. The $P$ and $S$ wave time delays are measured from the vertical and transverse components, respectively. Vertical lines denote the two time windows used in this study.

the double-difference relocation algorithm hypoDD [Waldhauser, 2001]. The refined hypocenters are within a few hundred meters to the original locations and build the data set used in this study.

[6] We calculated the cross correlation of all the possible pairs of events recorded at one borehole station (OT01, Figure 1) using a time window that covers both $P$ and $S$ waves to find potential similar events. OT01 was chosen for its long coverage and high-quality data. It has been operating since the network was installed in 1995, whereas the other borehole station, OT0a was installed in 1998. Two waveforms with a cross-correlation coefficient $(\mathrm{CC}) \geq 0.8$ were selected as preliminary candidates of similar events and were used for further analysis. We then expanded our $\mathrm{CC}$ measurements to all records for those potential similar events. We first converted the velocity seismograms to displacement records (see below for details) and then hand picked the $P$ and $S$ wave time windows. An example of the two picked time windows is shown in Figure 2. We then calculated the CC for both the $P$ and $S$ waves and counted numbers of stations with $\mathrm{CC} \geq 0.8$ for both $P$ and $S$ waves. If the number of stations with high $\mathrm{CC}$ values $(\geq 0.8)$ is greater than 6 and accounts for more than $80 \%$ of the total records, we defined them as similar events (time delays measured from pairs with $\mathrm{CC} \geq 0.9$ are used for relocation). We found in general the $\mathrm{CC}$ is closely related to the signalto-noise ratio (SNR) of the measured records; those with greater CC values usually have a larger SNR.

\section{Differential Time Measurements and Error Estimations}

[7] It is well known that it is possible to obtain subsample time precision through coherence measurements. In our study, we employed a cosine fitting method to estimate subsample delay time in the time domain [De Jong et al., 1990; Cespedes et al., 1995]. Given the largest sample of the correlation function, $\mathrm{CC}(0)$, and its two neighbors $\mathrm{CC}(-1)$ and $\mathrm{CC}(1)$, the estimated subsample shift is given by

$$
\tau=\alpha / \arctan \left(\frac{\mathrm{CC}(-1)-\mathrm{CC}(1)}{2 \mathrm{CC}(0) \sin \alpha}\right)
$$

where

$$
\alpha=\arccos \left(\frac{\mathrm{CC}(-1)+\mathrm{CC}(1)}{2 \mathrm{CC}(0)}\right) .
$$

The measured differential times were further confirmed with direct interpolation of either the two time series or the cross correlation functions.

[8] In general the measured differential time shows little dependence on the time window length except for the first half cycle which we will discuss in detail later (Figure 3). We chose to use a fixed time window, $0.15 \mathrm{~s}$ for both $P$ and $S$ waves, which covers at least two cycles of the $P$ and $S$ waves that have a dominant frequency higher than $15 \mathrm{~Hz}$ (Figure 2a).

[9] When the cross correlation method is used to measure the differential time between two highly similar wavelets, there exists a theoretical lower bound which places a limit on the performance of all unbiased time delay estimators. This limit is known as the Cramer-Rao Lower Bound (CRLB) [e.g., Carter, 1987; Walker and Trahey, 1995]. It predicts that the low bound in time delay measurements is directly related to SNR:

$$
\Delta t_{\mathrm{RMS}}=\frac{1}{\sqrt{2} \omega_{0} \mathrm{SNR}}
$$




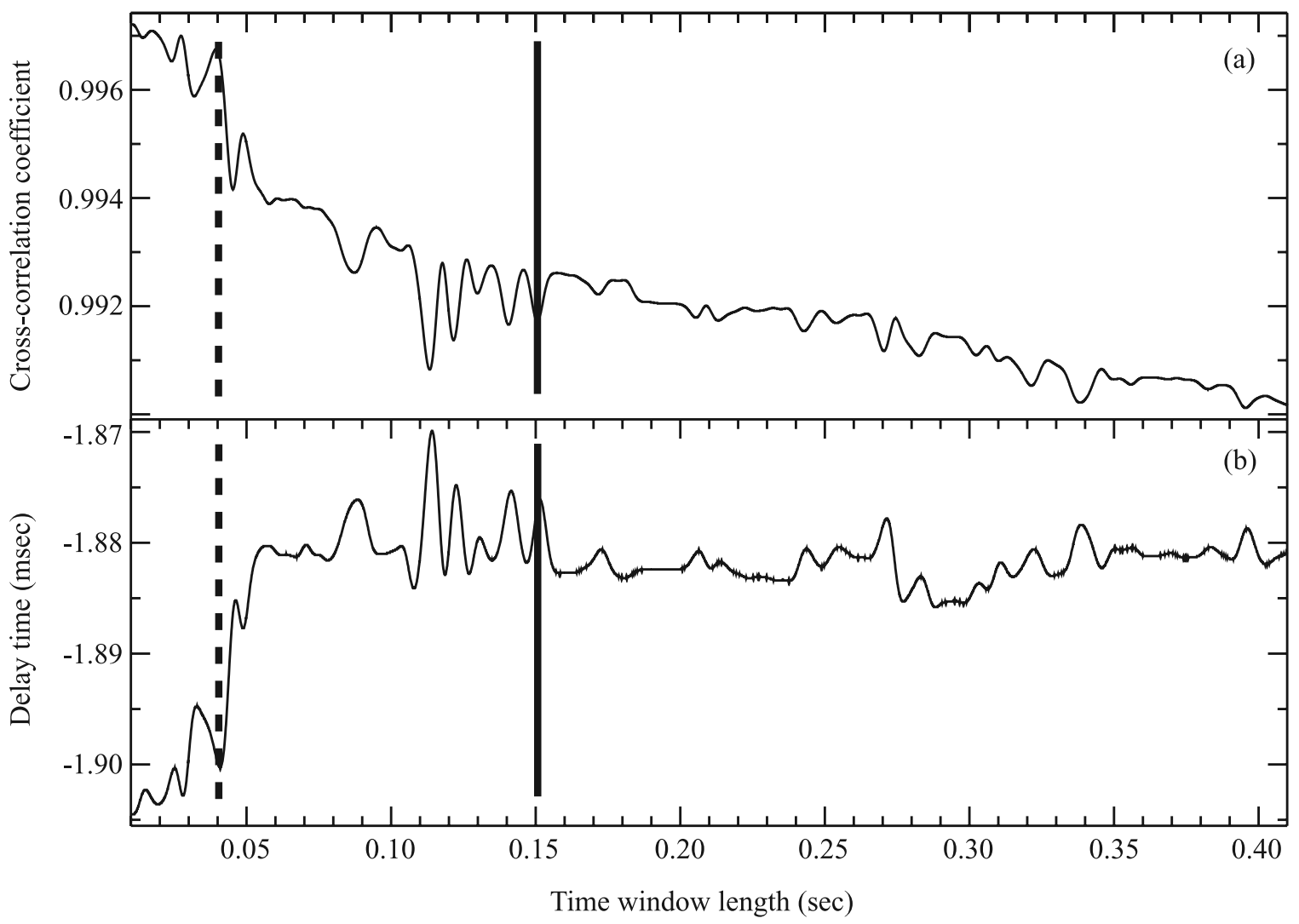

Figure 3. (a) Cross-correlation coefficient and (b) delay time measurements shown as a function of time window length for $P$ wave recorded at OT01 shown in Figure 2a. The two vertical lines defined the two time windows used in delay time measurements.

Here $\omega_{0}$ is the dominant angular frequency in the $P$ and $S$ wave time windows. Derivation of equation (2) is outlined in Appendix A. Equation (2) indicates that the SNR is the only parameter that controls the precision in our time delay estimation when the digitizing error is much less than the background noise. The precision is not controlled by the sampling rate of the digitizer and it is possible to obtain subsampling interval measurements of the time delay. The dominant frequency for our data is $30 \mathrm{~Hz}$ for the $P$ wave and $15 \mathrm{~Hz}$ for the $S$ wave, respectively. SNR is taken as the lower value computed from the two seismograms for calculating CC. Most of the data have SNR greater 10, which means that the estimated error is below $1 \mathrm{~ms}$. Since the rupture sizes of the analyzed events are in the range of a few meters to a few hundreds of meters, we rounded up our delay time measurements to one tenth millisecond. Therefore errors in the delay time estimations are between $0.1 \mathrm{~ms}$ and $1 \mathrm{~ms}$.

[10] An alternative way to estimate error is to use internal inconsistency existing in the delay times between the pairs in a multiplet. For a multiplet with three events, for example, we can obtain three $S-P$ differential times for three pairs, $\Delta T_{12}^{o}, \Delta T_{13}^{o}$, and $\Delta T_{23}^{o}$. Among the three differential times, only two are independent. In other words, we can calculate $\Delta T_{23}^{c}$ from $\Delta T_{12}^{o}$ and $\Delta T_{13}^{o}$. The inconsistency between the measured $\Delta T_{23}^{o}$ and derived
$\Delta T_{23}^{c}$ can be considered as an index of the measurement error. We obtained a total of 201 inconsistency estimates varying in the range between approximately $-1 \mathrm{~ms}$ to $1 \mathrm{~ms}$ with an average of $0.02 \mathrm{~ms}$ and standard deviation of

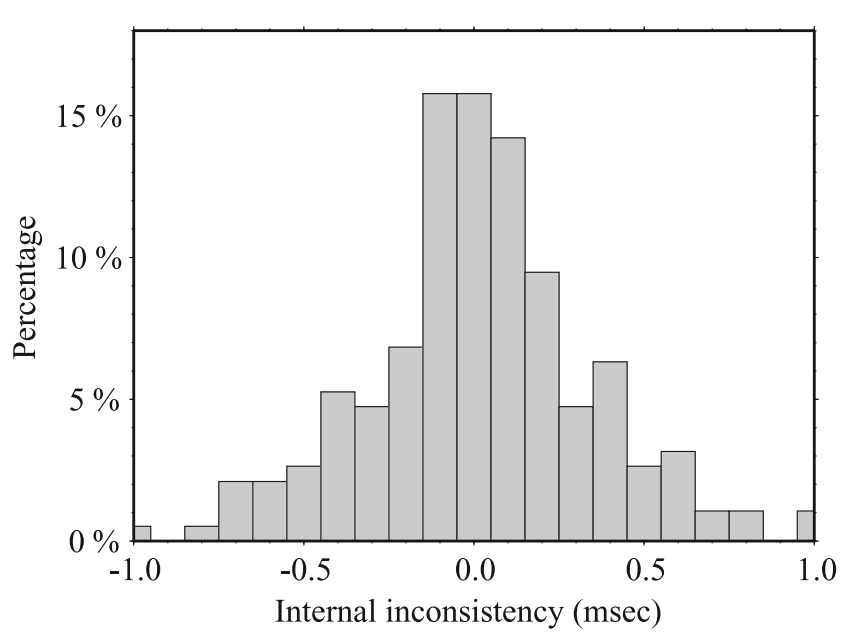

Figure 4. Histograms showing the distributions of internal inconsistency in the multiplet delay time measurements. See the text for details on the internal inconsistency. 
$0.2 \mathrm{~ms}$ (Figure 4), which is roughly consistent with the CRLB estimations.

\section{Earthquake Relocation and Distance Between Similar Events}

\subsection{Doublet Relocation}

[11] Following Got et al. [1994] and Rubin and Gillard [2000], we assumed that similar events are sufficiently close that all the differences in traveltimes may be ascribed solely to the different raypaths in the source region. To avoid the trade-off between origin time and event depth, instead of using $P$ or $S$ wave traveltimes, we used relative $S-P$ traveltimes to determine their relative locations. The relative $S$ - $P$ differential time, $\Delta T_{i j}^{k}$, between events $i$ and $j$ at station $k$ is expressed as:

$$
\Delta T_{i j}^{k}=\left(\Delta \mathbf{r}_{i j} \cdot \mathbf{n}_{\beta}^{\mathbf{k}}\right) / \beta-\left(\Delta \mathbf{r}_{\mathbf{i j}} \cdot \mathbf{n}_{\alpha}^{\mathbf{k}}\right) / \alpha,
$$

where $\Delta \mathbf{r}_{i j}$ is the relative position vector, $\mathbf{n}_{\alpha}^{k}$ and $\mathbf{n}_{\beta}^{k}$ are the unit vectors along the $P$ and $S$ rays to station $k$, respectively, $\alpha$ and $\beta$ are the $P$ and $S$ wave velocity in the source region. A three-dimensional (3-D) velocity model derived from a $P$ and $S$ wave tomographic study was used in calculating the takeoff angles.

[12] For each similar event pair we have a system of linear equations in the form

$$
\mathbf{G m}=\mathbf{d},
$$

where $\mathbf{G}$ is a $N \times 3\left(N\right.$ is the total number of $\Delta T_{i j}^{k}$ observations) matrix, $\mathbf{m}$ is a vector of length $3,[\Delta x, \Delta y$, $\Delta z]^{\mathrm{T}}$, containing the relative locations to be determined, $\mathbf{d}$ is the data vector of the observed $S-P$ differential times. We further introduced a weight to each of the equations in (3) and used the normal inversion scheme:

$$
\mathbf{m}=\left(\mathbf{G}^{\mathbf{T}} \mathbf{W}_{\mathbf{N}} \mathbf{G}\right)^{-1} \mathbf{G}^{\mathbf{T}} \mathbf{W}_{\mathbf{N}} \mathbf{d} .
$$

Here $\mathbf{W}_{\mathbf{N}}$ is a diagonal matrix made by the weights introduced to equation (4). $\mathbf{W}_{\mathbf{N}}$ is calculated from a biweight function to downweight large anomalous data and also data with large errors. We used the same biweight function proposed by Mosteller and Tukey [1977]

$$
W_{k}=\max ^{2}\left(0,1-\left(\frac{R_{k}}{\alpha R_{\mathrm{med}}}\right)^{2}\right),
$$

where $R_{k}=\Delta T_{k}-\Delta \tau_{k}$ is the time residual. $\Delta \tau_{k}$ is time delay computed for the $k$ th station on the basis of known relative relocations, and $R_{\text {med }}$ is the median of the set of absolute values of $R_{k}$. This weight function rejects observations that give residuals whose absolute value is $\alpha$ times greater than the median; $\alpha$ is usually chosen between 4 and 6 and we have used 4 in this study.

[13] On the basis of the CRLB error measurements we constructed the diagonal data covariance matrix, $\mathbf{C}_{\mathbf{d}}$. With the biweight function and data covariance matrix, we can construct $\mathbf{W}_{\mathbf{N}}$,

$$
\mathbf{W}_{\mathrm{N}}=\mathbf{W}_{\mathrm{k}} \mathbf{C}_{\mathrm{d}}^{-1}
$$

The initial solution was obtained by assigning unit weights for $\mathbf{W}_{\mathbf{k}}$. The inversion process was then iterated and the weighting factor $\mathbf{W}_{\mathbf{k}}$ and $\mathbf{W}_{\mathbf{N}}$, were updated at each step. The process was terminated when either the root-meansquare (RMS) residual reached a constant value or the maximum number of iterations was reached. Usually, it took only a few iterations to reach the final solution.

\subsection{Multiplet Relocation}

[14] In the case of a multiplet, we are basically solving a similar linear system with an increased number of observations and unknowns. $\mathbf{G}$ becomes a $N \times 3(M-1)$ matrix where $N$ is the total number of observations $\left(\Delta T_{i j}^{k}\right), M$ is the total number of events in the multiplet; $\mathbf{m}$ becomes a vector of length 3(M-1), $\left[\Delta x_{2}, \Delta y_{2}, \Delta z_{2}, \ldots, \Delta x_{M}, \Delta y_{M}, \Delta z_{M)}\right]^{\mathrm{T}}$, which are the locations relative to the first event. $\mathbf{d}$ is still the data vector of the observed $S-P$ differential times.

\subsection{Relocation Errors}

[15] To estimate relocation errors, we first calculated model covariance matrix based on the following equation:

$$
\mathbf{C}_{\mathbf{m}}=\left(\mathbf{G}^{\mathbf{T}} \mathbf{W}_{\mathbf{N}} \mathbf{G}\right)^{-1} .
$$

We then took the square root of the diagonal elements of $\mathbf{C}_{\mathbf{m}}$ as the errors in the relative locations. Relocation errors estimated from this method range from a few tenths of meters to about $10 \mathrm{~m}$. Generally, errors estimated from the covariance matrix are believed to be underestimated [Got et al., 1994].

[16] To obtain a better estimation on the location errors, we used a rather straight forward grid searching method. We defined a 3-D region surrounding the event locations determined by the above inversions with a set of grid points. For each grid point we calculated the RMS residual time using the same weighting parameter described in equation (6). The relocation uncertainty thus can be directly estimated from the uncertainties in the $S-P$ time measurements (Figure 5). The location error corresponding to a $0.1 \mathrm{~ms}$ uncertainty (estimated from CRLB) in delay time measurements is a few meters, several times larger than those estimated from the covariance matrix method.

\section{Estimation of Scalar Moment and Rupture Size}

[17] To compare the distances between the similar events with rupture sizes, it is necessary to have an objective measure of earthquake size. In this study we used the Brune model [Brune, 1970] to estimate the scalar seismic moment $M_{o}$ :

$$
M_{o}=\frac{4 \pi \rho c^{3} R \Omega_{o}}{U_{\varphi \theta}} .
$$

Here $\Omega_{o}$ is the displacement spectrum at zero frequency or the permanent displacement [Abercrombie, 1995]. $\rho, c, R$, and $U_{\varphi \theta}$ are density $\left(2700 \mathrm{~kg} / \mathrm{m}^{3}\right)$, seismic wave velocity $(5.50 \mathrm{~km} / \mathrm{sec}$ for $P$ waves and $3.18 \mathrm{~km} / \mathrm{sec}$ for $S$ waves), hypocentral distance (in meters) and a correction term for radiation pattern, respectively. The spherical average of radiation patterns are 0.52 and 0.63 for $P$ and $S$ waves, respectively [Aki and Richards, 1980; Abercrombie, 1995]. 

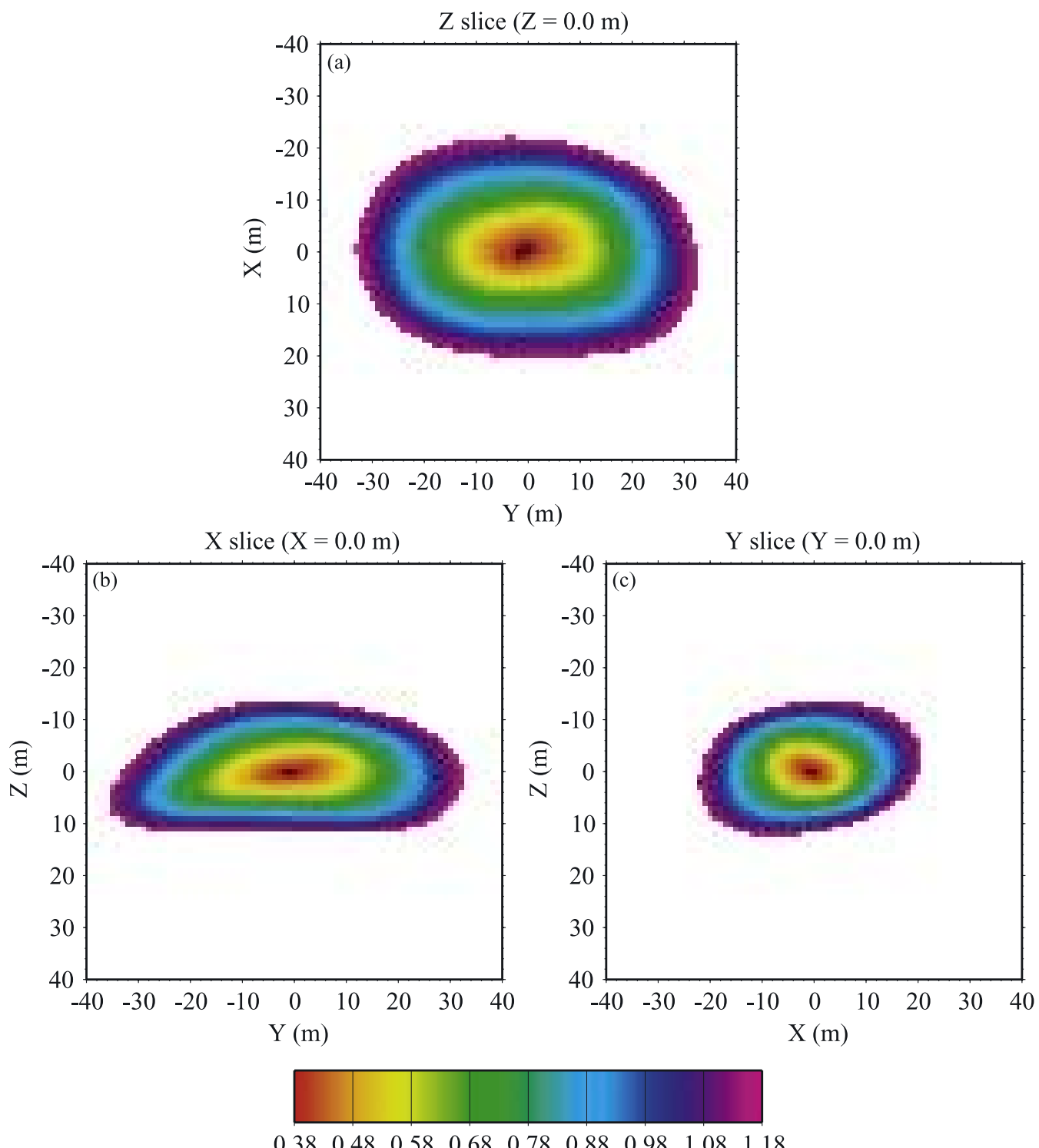

Figure 5. Three normal direction slices showing 3-D shape of the uncertainties with a grid search method. Amplitude is the $S-P$ residual in millisecond.

[18] The long-period amplitude $\Omega_{o}$ was estimated by fitting displacement spectra. The $\omega^{2}$ model of Brune [1970] and the revised model by Boatwright [1978] shown in equations (10) and (11), respectively, were used to fit the $P$ and $S$ wave amplitude spectra:

$$
\begin{gathered}
\Omega(\omega)=\frac{\Omega_{o} \mathrm{e}^{-\frac{\omega t}{2 Q}}}{1+\left(\omega / \omega_{c}\right)^{2}}, \\
\Omega(\omega)=\frac{\Omega_{o} \mathrm{e}^{-\omega t / 2 Q}}{\left[1+\left(\omega / \omega_{c}\right)^{4}\right]^{0.5}} .
\end{gathered}
$$

Here $\omega$ and $\omega_{c}$ are the angular frequency and corner frequency, respectively. $Q$ and $t$ are the quality factor and the arrival time of the $P$ or $S$ wave. The Boatwright model has a sharper corner than the Brune model. In equations (10) and (11), we have three free parameters, $\Omega_{o}$, $\omega_{c}$ and $Q$, to fit. We found that $Q$ is less well constrained compared to the other two parameters. We thus used a constant $Q$ model $\left(Q_{\mathrm{p}}=300, Q_{\mathrm{s}}=560\right.$ [Stork and Ito, 2004; Imanishi et al., 2004]) and searched for the $\Omega_{o}$ and $\omega_{c}$ that best fit the observed $P$ and $S$ wave spectra.

[19] To estimate the displacement spectra, we first converted velocity records to displacement by a deconvolution of the instrument response. The typical frequency response for a velocity transducer to ground velocity can be simplified as [Aki and Richards, 1980]

$$
I(\omega)=\frac{G \omega^{2}}{-\omega^{2}+2 i h \omega_{0} \omega+\omega_{0}^{2}},
$$




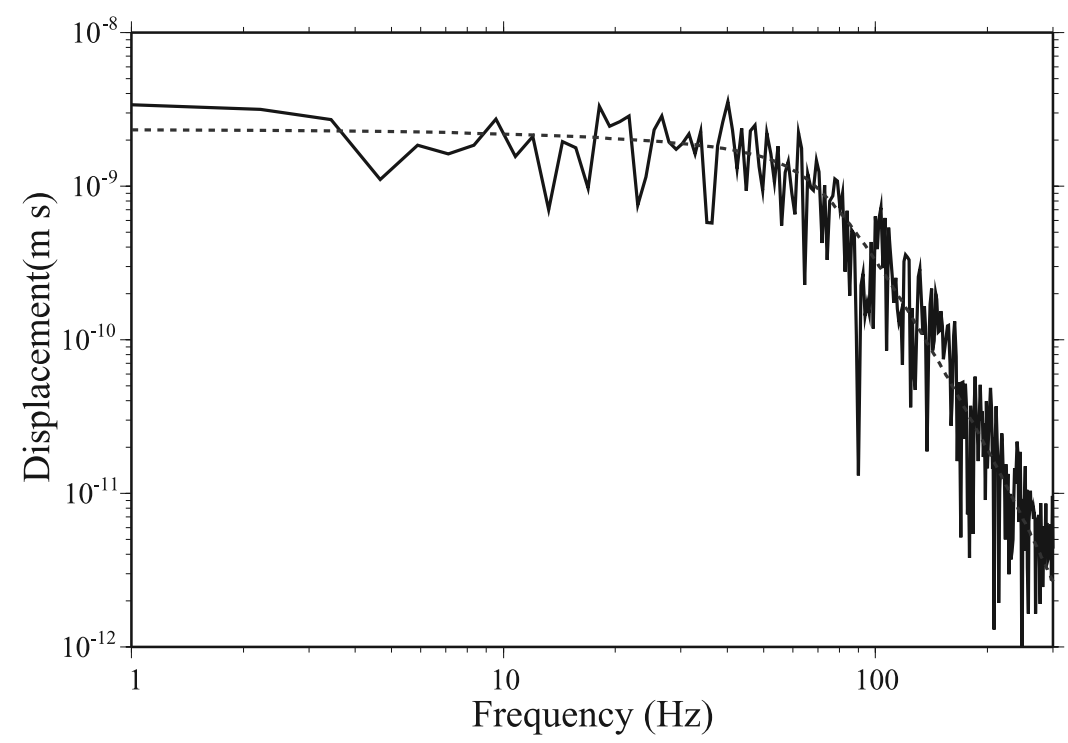

Figure 6. An example of the observed amplitude spectrum (solid line) at the 800-m-deep borehole station OT0a shown with the best fitting Brune [1970] $\omega^{2}$ source model (dashed line).

where $\omega_{0}$ is the natural frequency of the sensor $(2 \pi \times 2 \mathrm{~Hz})$, $h$ is the damping constant, and $G$ is the gain factor.

[20] We used data recorded at the 800-m-deep borehole station (OT0a) to determine the scalar moment $M_{o}$. Figure 6 shows an example of the spectrum of the $P$ wave from the vertical component. We used Levenberg-Marquardt algorithm [Bates and Watts, 1988] in finding the best fitting value of $M_{o}$. On average the Boatwright model fit better than the Brune model did, although the difference was trivial. We computed $M_{o}$ from $P$ and $S$ waves, and the average value of the two was taken as the $M_{o}$ estimate. Our estimates are consistent with those estimated by Imanishi et al. [2004] but are systematically higher than the values of Stork and Ito [2004]. The magnitude estimated by Stork and Ito [2004] was calculated from the dominant components (vertical for $P$, radial for $S V$ and transverse for $S H$ ) only, we found significant energies in the minor components, for example, $P$ in the radial and $S V$ in the vertical components, which may explain the lower values of Stork and Ito [2004].

[21] The magnitude in the catalog was the Japan Meteorological Agency (JMA) magnitude $\left(M_{j}\right)$. Since the 800-mdeep borehole seismometer was installed in 1998, we could not estimate $M_{o}$ with this station for events that occurred before 1998. We therefore used the moment $M_{o}$ estimated from the data after 1998 to calibrate the JMA magnitude with a linear regression

$$
\log M_{0}=0.95 M_{j}+9.9
$$

Equation (13) is very close to what Abercrombie [1996] observed in southern California. The above relationship was then used to estimate $M_{o}$ from $M_{j}$ for events that occurred before 1998. Assuming a circular rupture model, we can estimate rupture radius, $a$, from $M_{o}$ under a given stress drop $(\Delta \sigma)$ by using the equation from Kanamori and Anderson [1975]:

$$
a=\left(\frac{7 M_{0}}{16 \Delta \sigma}\right)^{1 / 3}
$$

\section{Results and Discussions}

[22] Within the 21,000 microearthquakes we found only 807 similar events. These similar events comprise 278 doublets and 62 multiplets. The ratio of similar events to the entire seismicity $(<4 \%)$ is extremely low compared to those found on the San Andreas Fault near San Juan Bautista and in southern California [Rubin and Gillard, 2000; Shearer et al., 2005] where over $60-70 \%$ of the seismicity were identified to be similar events. All the doublets and multiplets in our study area occurred within a few days. The locations of the similar events appear to be random (crosses in Figure 1). There is, however, a narrow peak in the distribution of normal distance of these similar events to the fault plane (Figure 7a). Such a peak can also be seen from the entire seismicity (Figure 7b), although there is a small shift in the location of the peak. We interpret this peak as the true location of main shock fault.

[23] We found that relocation errors are generally in the range of several meters to a few tens of meters depending mainly on the uncertainties in the delay time measurements and station coverage. As mentioned in the previous section, we saw a systematic difference in delay times measured from the first half cycle and the whole wavelet (Figure 3). We performed a second relocation with the delay times measured from the short time window and found a discrepancy as much as $30 \mathrm{~m}$ from the locations estimated from the $S$ - $P$ times measured from the $0.15 \mathrm{~s}$ window. We also found that the discrepancy roughly increases with the magnitude 

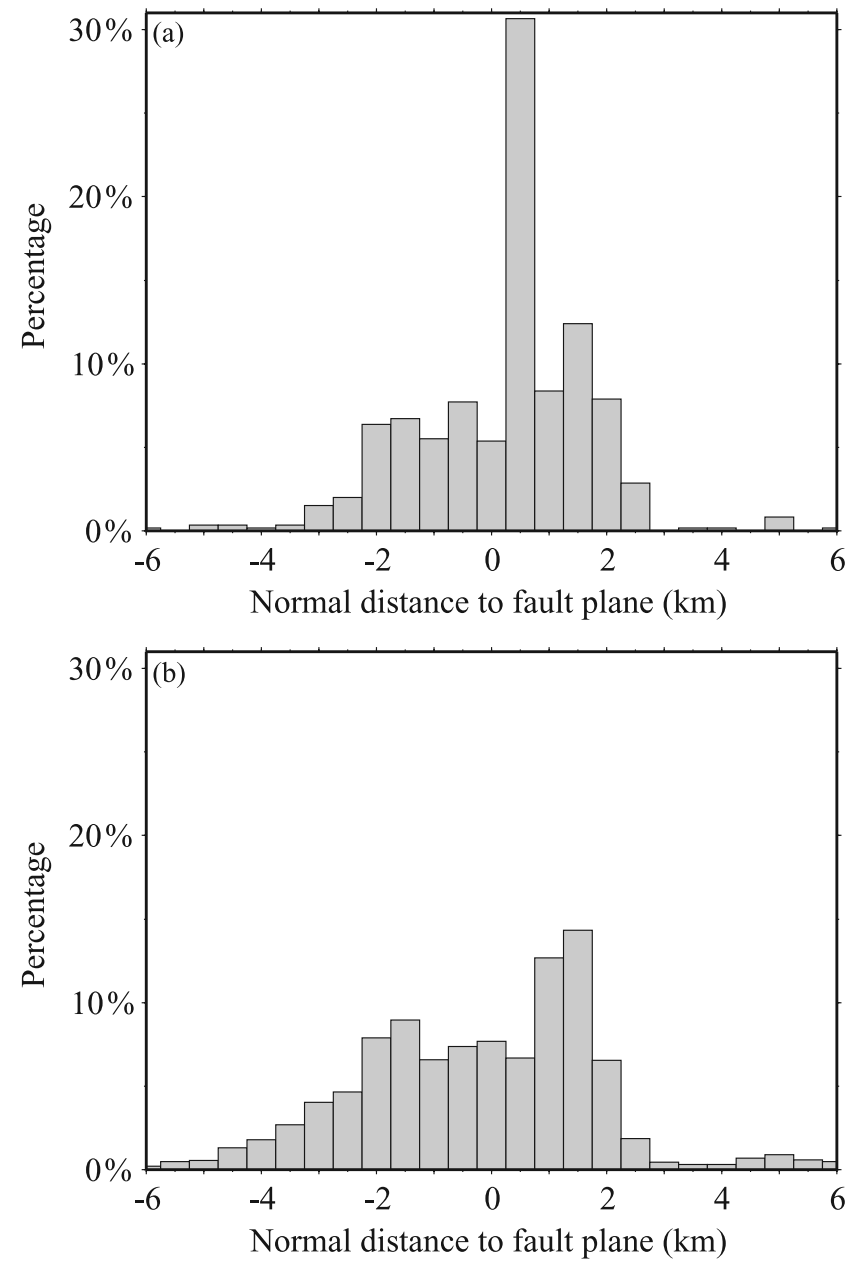

Figure 7. Histograms showing the distributions in the normal distance to the fault plane of the 1984 earthquake for (a) the similar events and (b) the entire seismicity. Note there is peak around $0.5 \mathrm{~km}$, which we interpret as the real fault zone of the earthquake.

of the larger event of the pair (Figure 8). In general, the magnitude difference between the two events in a pair also shows an increase with the larger event size. An increase of magnitude difference could result in a decrease of waveform similarity and therefore an increase of measurement error in delay time and event location. The average $\mathrm{CC}$ of each pair, however, does not show any dependence on event magnitude. It is thus hard to explain the above observation solely by an increasing of location error with event magnitude. We speculate that the observed discrepancy may reflect the finite size nature of earthquake ruptures. It is likely that the short time window measures the relative location between the initial points, while the long time window gives the relative locations of the centroids and the two could be different.

[24] To obtain a better comparison between event distances and their rupture sizes, we first projected the relative location vectors onto the 1984 earthquake fault plane and its normal direction (Figure 9). It is conceivable that the rupture planes of the events within the fault zone are probably more or less parallel to the 1984 fault plane whereas the others could have more random fault planes.
We thus divided the similar events into "on-fault" and "offfault" groups and projected them separately. In general there is no significant difference between the two groups in distribution of distance and colatitude. Distance between the consecutive pairs varies from $\sim 5 \mathrm{~m}$ to $\sim 100 \mathrm{~m}$ with a peak around $20 \mathrm{~m}$ (Figures 9a and 9d). The relative location vector shows an even distribution in colatitude direction (Figures $9 \mathrm{~b}$ and 9e), suggesting the fault planes of these small events are either not on the same plane or not parallel to the main fault. There is, however, a clear pattern in the distribution of longitude for events near the main fault plane. The second rupture tends to occur along the strike direction (Figure 9c), which is not seen in the case of the off-fault events (Figure 9e). Recent studies [e.g., Stein, 1999] have shown that the spatial distribution of aftershocks agrees well with the rupture-induced change in Coulomb stress. If this is true, then our observations on the spatial distribution of the immediate aftershocks suggest that most of the on-fault earthquakes are strike-slip events, whereas the off-fault ones are not necessarily strike-slip events.

[25] Following Rubin and Gillard [2000], we plotted the distance to the second events as a function of the magnitude $\left(M_{j}\right)$ of the first event (Figure 10a). Here the on-fault
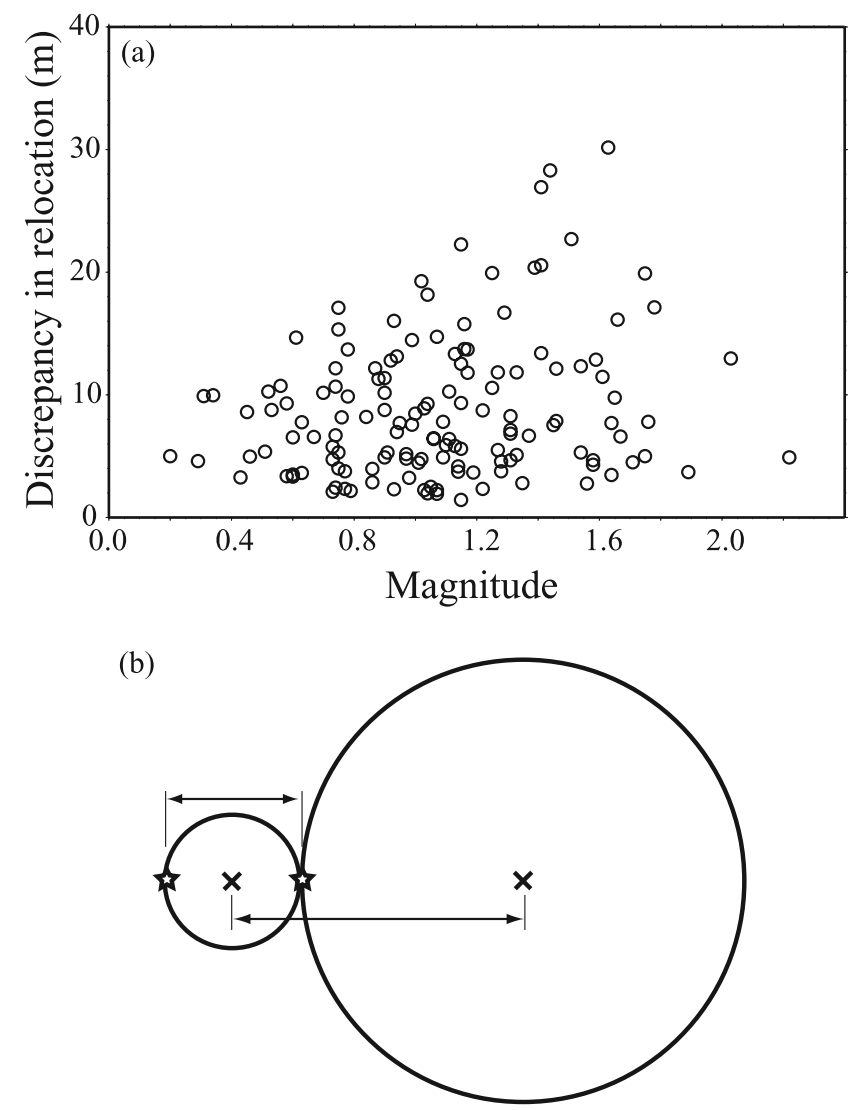

Figure 8. (a) Discrepancy in the relative locations arising from choosing different time windows. It appears to increase with the magnitude of the larger event in the pair. The two time windows are indicated in Figure 2. (b) Schematic diagram showing discrepancy in relative locations between rupture initials and centroids. This discrepancy is most likely due to the finite size nature of earthquake ruptures. 

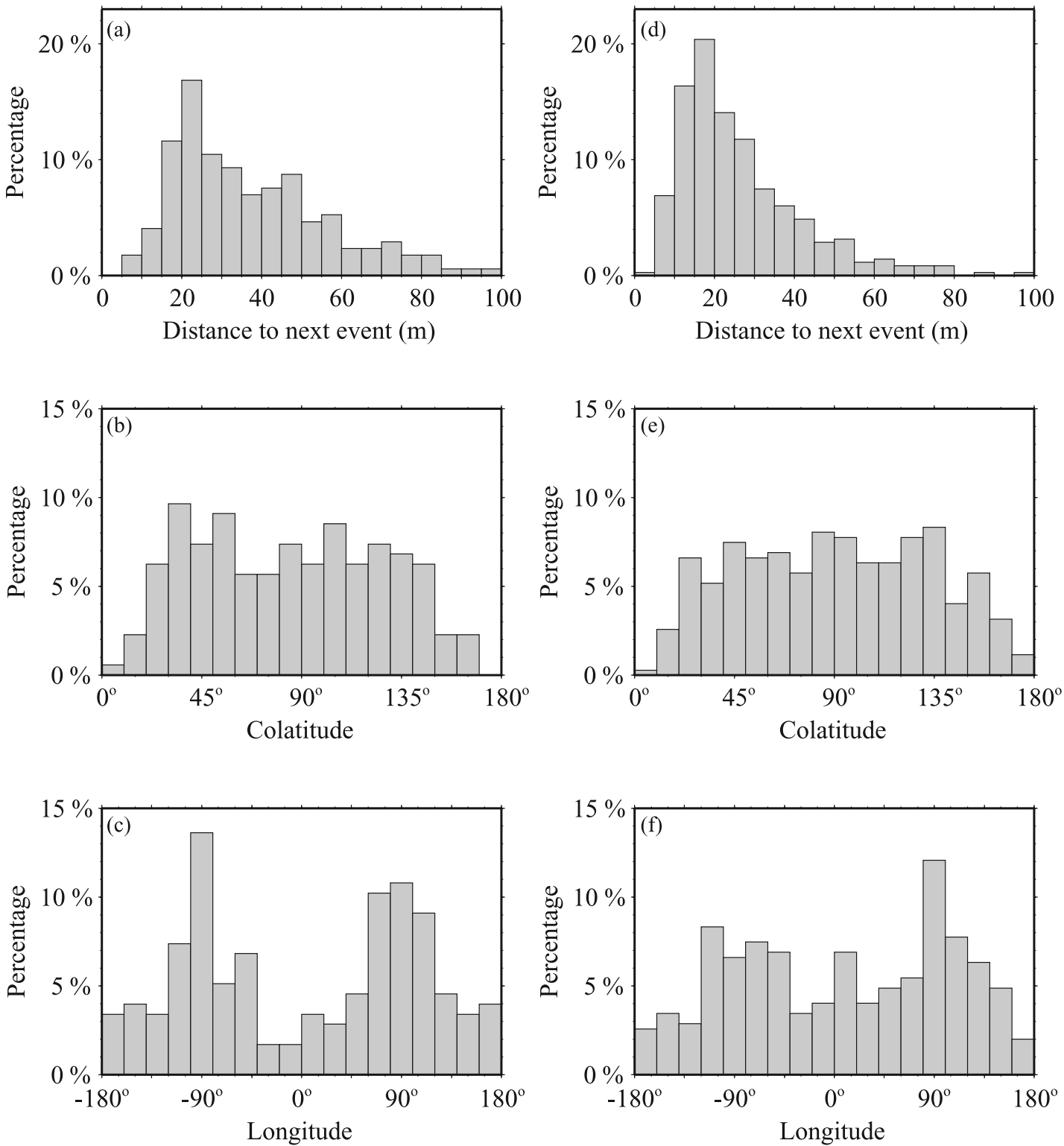

Figure 9. Histograms showing the distributions of the relative location vectors in amplitude, colatitude, and longitude for $(a, b, c)$ the on-fault and $(d, e, f)$ the off-fault events. The colatitude and longitude are defined in a spherical coordinate with the fault normal as pole and the fault plane as equator. Colatitude is the angle between the relative location vectors and the fault normal. The longitude is defined as the clockwise angle between the projection of the relative location vector onto the fault plane and the downdip direction. Note the relative location vectors of the on-fault events show a relatively even distribution in colatitude direction (Figure 9b) and are concentrated in the strike direction (Figure 9c).

and off-faults events are shown separately. It appears that there is a minimum distance for each magnitude and the value of this minimum distance increases with magnitude (Figure 9a). There is also a systematic difference between the two groups of events. The on-fault group (solid squares) has a relatively larger low cut compared to the off-fault group (open circles). For comparison, we have also shown the rupture radii for a circular fault model calculated from a stress drop of $10 \mathrm{MPa}$ (solid line) and $50 \mathrm{MPa}$ (dashed line) in Figure 10a. They correspond roughly to the minimum distances of the two groups. The linear trends of the low cut thus suggest that these similar events should be considered as consecutive events rather than repeating earthquakes.

[26] This can be further confirmed by projecting the "normalized" relative location vectors onto the fault plane (Figure 10b). A colatitude range of $60^{\circ}-120^{\circ}$ was used here in selecting the events. The rupture radii corresponding to a stress drop of $50 \mathrm{MPa}$ were used in the normalization. Again the two groups are shown separately. The solid circle denotes the rupture area for a stress drop of $10 \mathrm{MPa}$. We can see a small "hole" in the center of plot. Most of the events are located outside the unit circle (dashed line) whereas all on-fault events lie farther out of the $10 \mathrm{MPa}$ 

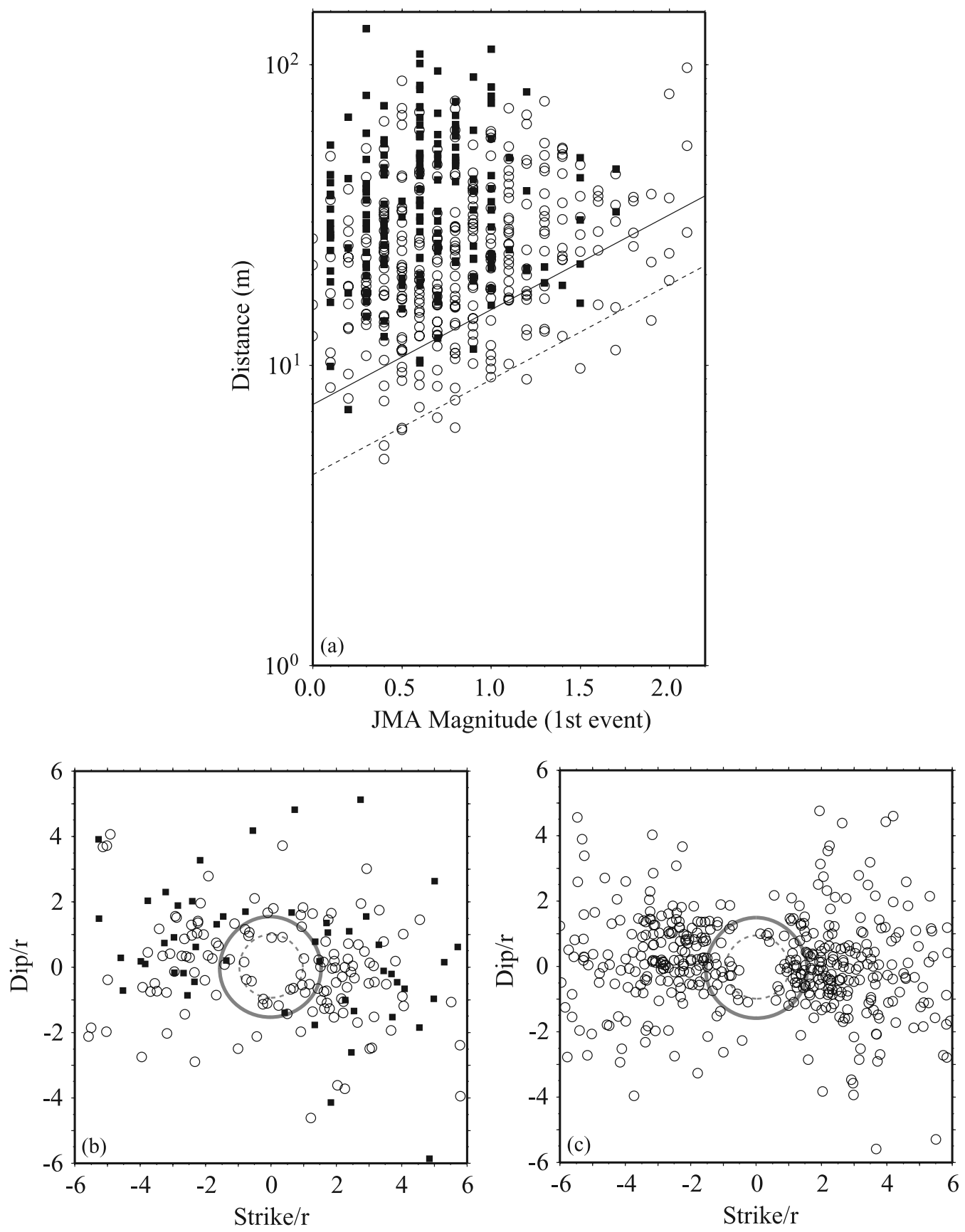

Figure 10. (a) Distances between consecutive earthquakes as a function of magnitude of the first events. The solid and dashed lines denote the rupture radii calculated from stress drops of 10 and $50 \mathrm{MPa}$, respectively. The on-fault and off-fault events are shown in solid squares and open circles, respectively. (b) Normalized relative location vectors projected onto the fault plane. A colatitude range of $60^{\circ}-120^{\circ}$ is used in selecting the pairs. The rupture radii corresponding to a stress drop of 10 and $50 \mathrm{MPa}$ are shown as solid and dashed line circles, respectively. The latter is used in the normalization. Note the small "hole" in the center of the plot. (c) Same projection as Figure $10 \mathrm{~b}$ to vertical fault planes containing the relative location vectors.

circle. If we assume that the similar events have vertical fault planes containing the relative location vectors, we can also confirm the presence of the central hole in a similar projection for all the similar events including those outside the $60^{\circ}-120^{\circ}$ colatitude range (Figure 10c).

[27] We assumed that the identified doublets and multiplets share the same rupture planes when we used the minimum distance to infer stress drop in Figure 10. Here we argue the validity of this coplanar assumption from the following two aspects. First, Yukutake et al. [2007] found that most of the on-fault earthquakes are strike-slip events with fault planes more or less parallel to the main shock fault plane. So if the coplanar assumption is valid, then the relative location vectors should also align with the main 

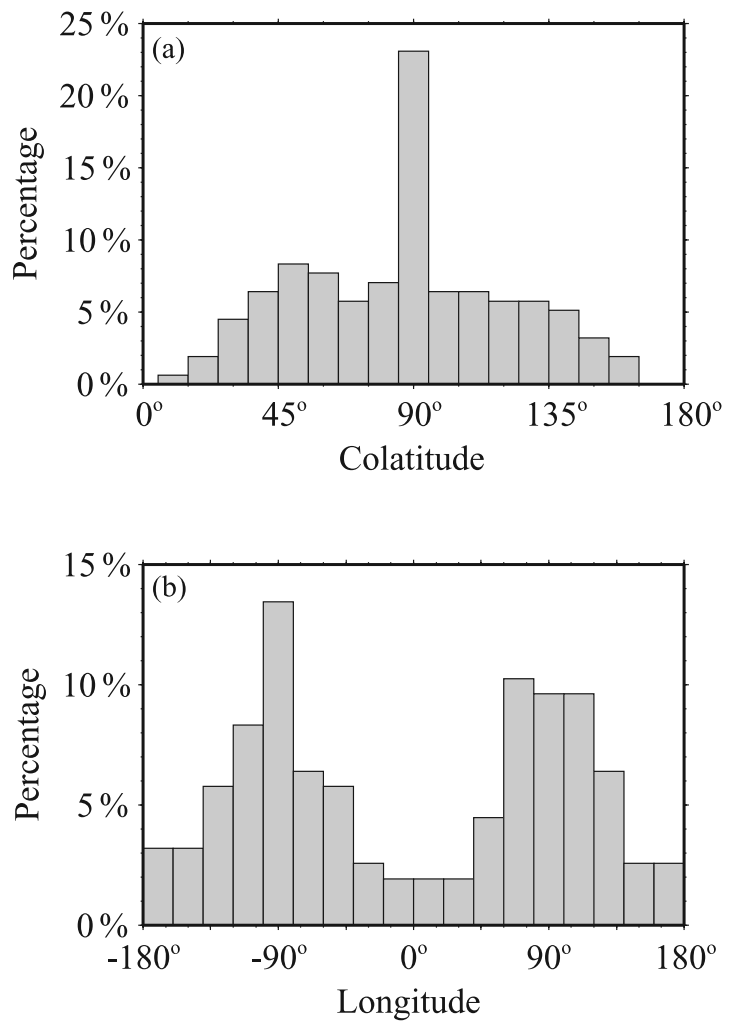

Figure 11. Histograms showing the distributions of the relative location vectors in colatitude and longitude with a conditional inversion. Note the large $90^{\circ}$ spike in (a) colatitude direction and (b) the relative concentration in the strike direction.

fault plane, which is not shown in the locations that best fit the $S$ - $P$ times (Figure 9). It is, however, possible to find relative location vectors aligning with the main fault within the uncertainties in $S-P$ times (Figure 5). With a conditional inversion, we can obtain a set of location vectors that exhibit a well-defined $90^{\circ}$ spike in colatitude direction, suggesting that most of the location vectors are also parallel to the main fault plane (Figure 11). Second, if the multiplets are coplanar, then the relative location vectors among the earthquakes must lie within the same plane. We applied a multivariable regression to determine how well these vectors are confined in a plane. The $\mathrm{R}$ square of the largest six multiplets (the largest multiplet in our data set consists of 10 events) varies from 0.71 to 0.97 with an average of 0.84 , so we concluded that the vectors in each multiplet are indeed located in the same plane.

[28] The lack of repeating earthquakes could have many reasons. Our catalog covers only 6 years, and it might not be long enough to observe earthquake repeating when the tectonic loading rate is low. Recurrence intervals observed at San Andreas Fault vary from days to years depending on event size [Nadeau and McEvilly, 1999; Peng et al., 2005]. Waldhauser and Ellsworth [2002] found a repeat rate of approximately 6 years at an observed surface creep rate of about $5 \mathrm{~mm} / \mathrm{yr}$ (long-term $9 \mathrm{~mm} / \mathrm{yr}$ ) when they study the Hayward fault, California. Kimata et al. [2004] observed an uplift of 3-6 mm in the study area during 2002-2004. If the same deformation rate is present before 2001 (this is probably true because there is no significant increase of seismicity in 2002-2004), then we would expect microearthquakes to repeat within the 6-year period, even if we assume a loading rate that is 10 times lower than that of the San Andreas Fault. We thus attribute the lack of repeating earthquake to the absence of a weak damaged zone along the main fault, which undergoes stable creep under steady tectonic loading. This weak zone is seismically distinct from the wall rocks by a reduced velocity of a few tens of percent [Li et al., 2003] and produces characteristic propagation signals, such as fault zone trapped waves. Fault zone trapped waves arise from coherent reflections between fault zone and wall rocks and have relatively large amplitude and long durations [ $\mathrm{Li}$ et al., 2003]. We found no evidence for such trapped waves associated with the main fault, suggesting that the damage zone of the 1984 earthquake has been healed almost completely. There are also no distinct low-velocity anomalies near the fault in our preliminary tomographic images.

[29] Our observations on the distances between consecutive pairs, however, are consistent with what Rubin and Gillard [2000] have observed at the San Andreas Fault, suggesting rupture physics between the two different fault systems is probably the same. The lack of "immediate" repeaters is further used by Rubin and Gillard [2000] to argue that microearthquakes they have studied are probably not triggered by the model proposed by Segall and Rice [1995]. In this model changes in pore pressure associated with coseismic slip and the postseismic fluid diffusion are used to explain the stabilization of one rupture and a subsequent immediate recurrence. We thus conclude that this model does not work in our study area either.

[30] If we assume that the observed minimum distances reflect the rupture size of the first events, by using equation (14) we obtained a stress drop of $10 \mathrm{MPa}$ for the on-fault group and $50 \mathrm{MPa}$ for the off-fault group, respectively. Since we have assumed that the consecutive event pairs occurred on the same fault planes and that these planes are parallel to the 1984 earthquake fault, our estimates presented here represent the upper bound of the stress drops. It is very likely that the above assumptions are more valid for the on-fault events. We thus consider the $10 \mathrm{MPa}$ is more representative to the corresponding stress drop of these microearthquakes. Because of the assumptions and the small amounts of the pairs used here it seems to be difficult to argue whether or not this stress drop depends on event size from the minimum distance versus magnitude relationship.

[31] The estimated stress drop here is consistent with the observation of Rubin and Gillard [2000]. They obtained a maximum of $10 \mathrm{MPa}$ stress drop at the San Andreas Fault, while the median stress drop at the San Andreas Fault estimated by Abercrombie [1995] is about 3 MPa. Using the same data set, Stork and Ito [2004] and Imanishi et al. [2004] have estimated the stress drops for these microearthquakes to be in the range of $0.01-10 \mathrm{MPa}$ and $0.1-$ $2 \mathrm{MPa}$, respectively. Our estimate is several times larger than their values. Since there are large uncertainties in estimating the corner frequency, $\omega_{c}$ in fitting spectra, the 
stress drops calculated from it could have very large errors. Also in our method we have assumed that the observed minimum distance equals to the rupture radius of the first event, this could be inappropriate if the second rupture occurred in a different plane from the first one. In addition, if the slip along the fault is very heterogeneous, it will result in a large deviation between the slip centroid and the center of the rupture area. Considering the above facts, we conclude that the discrepancy from the two methods is not significant.

\section{Conclusions}

[32] We have investigated the spatial and temporal distribution of similar microearthquakes occurred at the aftershock zone of the 1984 western Nagano earthquake in central Japan to understand fault evolution and rupture interactions. We found no evidence for repeating earthquakes at this intraplate fault. Together with other seismic investigations, we attribute the lack of repeating earthquakes to the absence of low-velocity damage zone along the fault. We observed a total of 807 similar events in the period of 1995-2001, which accounts for less than $4 \%$ of the total seismicity. These events occurred very closely in time, ranging from a few seconds to days. Precise relocation showed that these events are separated by a few meters to about $100 \mathrm{~m}$. There is a clear lower bound in distance between events and the minimum appears to be proportional to the size of the first events. By assuming the minimum distances as the rupture radii, we obtained a maximum stress drop of $10 \mathrm{MPa}$ for these events.

\section{Appendix A: Error Estimation of Time Delay}

[33] Following Aki and Richards [1980], we assume that a seismogram $d(t)$ consists of signal $s(t)$ and noise $n(t)$ :

$$
d(t)=s(t)+n(t)
$$

In the frequency domain, equation (A1) can be written as

$$
|D(\omega)| \exp \left[i \varphi_{d}(\omega)\right]=|S(\omega)| \exp \left[i \varphi_{s}(\omega)\right]+\left|N_{T}(\omega)\right| \exp \left[i \varphi_{n}(\omega)\right]
$$

Here the noise spectrum is estimated in a time window before the first arrival. For small $\left|N_{T}(\omega)\right| /|S(\omega)|$, the measured phase from the data is

$$
\varphi_{d}(\omega)=\varphi_{s}(\omega)+\frac{\left|N_{T}(\omega)\right|}{|S(\omega)|} \sin \left[\varphi_{n}(\omega)-\varphi_{s}(\omega)\right]
$$

The second term in equation (A3) is the phase fluctuation due to the noise. For a white noise $n(t), \varphi_{n}(\omega)-\varphi_{s}(\omega)$ is randomly and uniformly distributed from 0 to $2 \pi$, error in $\varphi_{n}(\omega)-\varphi_{s}(\omega)$ thus can be calculated as

$$
\Delta \varphi_{\mathrm{RMS}}=\frac{1}{\sqrt{2}} \frac{\left|N_{T}(\omega)\right|}{|S(\omega)|} .
$$

If we assume the dominant angular frequency of the signal is $\omega_{0}$, then error in the time delay measurement is

$$
\Delta t_{\mathrm{RMS}}=\frac{\Delta \varphi_{\mathrm{RMS}}}{\omega_{0}}=\frac{1}{\sqrt{2} \omega_{0}} \frac{\left|N_{T}\left(\omega_{0}\right)\right|}{\left|S\left(\omega_{0}\right)\right|}=\frac{1}{\sqrt{2} \omega_{0} \mathrm{SNR}},
$$

where SNR is the signal-to-noise ratio.

[34] Acknowledgments. We thank the National Research Institute for Earth Science and Disaster Prevention of Japan for providing the data. The Associate Editor, Felix Waldhauser, and two reviewers, Allan Rubin and Yong-gang $\mathrm{Li}$, provided very constructive reviews that improved the manuscript significantly. This work was supported by NSF grants EAR0352134 and EAR-0352119.

\section{References}

Abercrombie, R. E. (1995), Earthquake source scaling relationships from -1 to $5 \mathrm{ML}$ using seismograms recorded at $2.5-\mathrm{km}$ depth, $J$. Geophys. Res., 100, 24,015-24,036.

Abercrombie, R. E. (1996), The magnitude-frequency distribution of earthquake recorded with deep seismometers at Cajon Pass, southern California, Tectonophysics, 261, 1-7.

Aki, K., and P. Richards (1980), Quantitative Seismology, Freeman, W. H., New York.

Bates, D. M., and D. G. Watts (1988), Nonlinear Regression and Its Applications, Wiley, New York.

Boatwright, J. (1978), Detailed spectral analysis of two small New York State earthquakes, Bull. Seismol. Soc. Am., 68, 1131-1177.

Brune, J. N. (1970), Tectonic stress and the spectra of seismic shear waves from earthquakes, J. Geophys. Res., 75, 4997-5009.

Carter, G. C. (1987), Coherence and time delay estimation, Proc. IEEE, 75, $236-255$.

Cespedes, I., Y. Huang, J. Ophir, and S. Spratt (1995), Methods for estimation of sub-sample time delays of digitized echo signals, Ultrason. Imaging, 17, 142-171.

De Jong, P. G. M., T. Arts, A. P. G. Hoeks, and R. S. Reneman (1990), Determination of tissue motion velocity by correlation interpolation of pulsed ultrasonic echo signals, Ultrason. Imaging, 12, 84-98.

Dodge, D. A., and G. C. Beroza (1997), Source array analysis of coda waves near the 1989 Loma Prieta, California, mainshock: Implications for the mechanism of coseismic velocity changes, J. Geophys. Res., 102, $24,437-24,458$

Ellsworth, W. L. (1994), Characteristic earthquakes and long-term earthquake forecasts: Implications of central California seismicity, in Urban Disaster Mitigation, edited by F. Y. Cheng and M.-S. Sheu, pp. 1-14, Elsevier, New York.

Got, J.-L., J. Fréchet, and F. Klein (1994), Deep fault plane geometry inferred from multiplet relative relocation beneath the south flank of Kilauea, J. Geophys. Res., 99, 15,375-15,386.

Horiuchi, S., K. Ito, T. Matsuzawa, and A. Hasegawa (1992), A real-time processing system of seismic wave using personal computers, J. Phys. Earth, 40, 395-406.

Igarashi, T., T. Matsuzawa, and A. Hasegawa (2003), Repeating earthquakes and interplate aseismic slip in the northeastern Japan subduction zone, J. Geophys. Res., 108(B5), 2249, doi:10.1029/2002JB001920.

Iio, Y., S. Ohmi, R. Ikeda, E. Yamamoto, H. Ito, Y. Kuwahara, T. Ohminato, B. Shibazaki, and M. Ando (1999), Slow initial phase generated by microearthquakes occurring in the western Nagano prefecture, Japan: The source effect, Geophys. Res. Lett., 26, 1969-1972.

Imanishi, K., M. Takeo, W. L. Ellsworth, H. Ito, T. Matsuzawa, Y. Kuwahara, Y. Iio, S. Horiuchi, and S. Ohmi (2004), Source parameters and rupture velocities of microearthquakes in western Nagano, Japan, determined using stopping phases, Bull. Seismol. Soc. Am., 94, 1762-1780.

Kanamori, H., and D. L. Anderson (1975), Theoretical basis of some empirical relations in seismology, Bull. Seismol. Soc. Am., 65, 10731095.

Kimata, F., et al. (2004), Ground uplift detected by precise leveling in the Ontake earthquake swarm area, central Japan in 2002-2004, Earth Planets Space, 12, 45-48.

Li, Y.-G., J. E. Vidale, K. Aki, F. Xu, and T. Burdette (1998), Evidence of shallow fault zone healing after the 1992 M 7.5 Landers, California, earthquake, Science, 279, 217-219.

Li, Y.-G., J. E. Vidale, S. M. Day, D. D. Oglesby, and E. Cochran (2003), Postseismic fault healing on the rupture zone of the 1999 M 7.1 Hector Mine, California, earthquake, Bull. Seismol. Soc. Am. 93, 854-869. 
Mosteller, F., and J. W. Tukey (1977), Data Analysis and Linear Regression, Addison-Wesley, Boston, Mass.

Nadeau, R. M., and T. V. McEvilly (1999), Fault slip rates at depth from recurrence intervals of repeating microearthquakes, Science, 285, 718-721.

Nadeau, R. M., W. Foxall, and T. V. McEvilly (1995), Clustering and periodic recurrence of microearthquakes on the San Andreas Fault at Parkfield, California, Science, 267, 503-507.

Niu, F., P. G. Silver, R. M. Nadeau, and T. V. McEvilly (2003), Stressinduced migration of seismic scatterers associated with the 1993 Parkfield aseismic transient event, Nature, 426, 544-548.

Peng, Z.-G., J. E. Vidale, C. Marone, and A. M. Rubin (2005), Systematic variations in recurrence interval and moment of repeating aftershocks, Geophys. Res. Lett., 32, L15301, doi:10.1029/2005GL022626.

Rubin, A. M., and D. Gillard (2000), Aftershock asymmetry/rupture directivity among central San Andreas Fault microearthquakes, J. Geophys. Res., 105, 19,095-19,109.

Schaff, D. P., and G. C. Beroza (2004), Coseismic and postseismic velocity changes measured by repeating earthquakes, J. Geophys. Res., 109, B10302, doi:10.1029/2004JB003011.

Segall, P., and J. R. Rice (1995), Dilatancy, compaction and slip instability of a fluid-infiltrated fault, J. Geophys. Res., 100, 22,155-22,171.

Shearer, P. M., E. Hauksson, and G. Lin (2005), Southern California hypocenter relocation with waveform cross-correlation, part 2: Results using source-specific station terms and cluster analysis, Bull. Seismol. Soc. Am., 95, 904-915.

Stein, R. S. (1999), The role of stress transfer in earthquake occurrence, Nature, 402, 605-609.

Stork, A. L., and H. Ito (2004), Source parameter scaling for small earthquakes observed at the western Nagano deep borehole, central Japan, Bull. Seismol. Soc. Am., 94, 1781-1794.
Waldhauser, F. (2001), hypoDD: A program to compute double-difference hypocenter locations (hypoDD version 1.0-3/2001), U.S. Geol. Surv. Open File Rep., 01-113.

Waldhauser, F., and W. L. Ellsworth (2002), Fault structure and mechanics of the Hayward fault, California, from double-difference earthquake locations, J. Geophys. Res., 107(B3), 2054, doi:10.1029/2000JB000084.

Walker, W. F., and G. E. Trahey (1995), A fundamental limit on delay estimation using partially correlated speckle signals, IEEE Trans. Ultrason. Ferrelectr. Freq. Control, 42, 301-308.

Yoshida, S., and K. Koketsu (1990), Simultaneous inversion of waveform and geodetic data for the rupture process of the 1984 Naganoken-Seibu, Japan, earthquake, Geophys. J. Int., 103, 335-362.

Yukutake, Y., Y. Iio, K. Takai, and S. Horiuchi (2007), The detailed spatial change in the stress field in the 1984 eastern Nagano Prefecture earthquake region, paper presented at Japan Geoscience Union Meeting, Chiba.

X. Cheng and F. Niu, Department of Earth Science, Rice University, 6100 Main Street, Houston, TX 77005, USA. (xcheng@rice.edu)

S. Horiuchi and K. Takai, National Research Institute for Earth Science and Disaster Prevention, 3-1 Tennodai, Tsukuba, Ibaraki, 305-0006, Japan.

Y. Iio, Research Center for Earthquake Prediction, Disaster Prevention Research Institute, Kyoto University, Gokajyo, Uji, Kyoto 611-0011, Japan.

H. Ito, Geological Survey of Japan, AIST Tsukuba Central 7, Tsukuba, Ibaraki, 305-8567, Japan.

P. G. Silver, Department of Terrestrial Magnetism, Carnegie Institution of Washington, 5241 Broad Branch Road, N.W., Washington, DC 20015, USA. 